\title{
Mechanical models to estimate the paleostress state from igneous intrusions
}

\author{
Tara L. Stephens ${ }^{1}$, Richard J. Walker ${ }^{1}$, David Healy ${ }^{2}$, Alodie Bubeck ${ }^{1}$, and Richard W. England ${ }^{1}$ \\ ${ }^{1}$ School of Geography, Geology and the Environment, University of Leicester, Leicester, LE1 7RH, UK \\ ${ }^{2}$ School of Geosciences, King's College, University of Aberdeen, Aberdeen, AB24 3UE, UK
}

Correspondence: Tara L. Stephens (tls15@le.ac.uk)

Received: 4 March 2018 - Discussion started: 21 March 2018

Revised: 15 June 2018 - Accepted: 21 June 2018 - Published: 9 July 2018

\begin{abstract}
Dikes and sills represent an important component of the deformation history in volcanic systems, but unlike dikes, sills are typically omitted from traditional paleostress analyses in tectonic studies. The emplacement of sheet intrusions is commonly associated with Mode I fracturing in a low deviatoric stress state, in which dilation is perpendicular to the fracture plane. Many natural examples of sills and dikes, however, are observed to accommodate minor shear offsets, in addition to a component of dilation. Here we present mechanical models for sills in the San Rafael subvolcanic field, Utah, which use field-based measurements of intrusion attitude and opening angles to constrain the tectonic stress axes during emplacement and the relative magma pressure for that stress state. The sills display bimodal dips to the NE and SW and consistent vertical opening directions, despite variable sill dips. Based on sill attitude and opening angles, we find that the sills were emplaced during a phase of NE-SW horizontal shortening. Calculated principal stress axes are consistent (within $\sim 4^{\circ}$ ) with paleostress results for penecontemporaneous thrust faults in the area. The models presented here can be applied to any set of dilational structures, including dikes, sills, or hydrous veins, and represent a robust method for characterising the paleostress state in areas where other brittle deformation structures (e.g. faults) are not present.
\end{abstract}

\section{Introduction}

Sills and dikes are traditionally treated as extension fractures with a dilation vector normal to the fracture wall; i.e. they are extension fractures (Mode I; e.g. Anderson, 1951). This assumption has important implications for the use of sheet intrusions in constraining tectonic stress states because the minimum compressive stress $\left(\sigma_{3}\right)$ is perpendicular to the extension fracture walls; local deflections of the intrusion attitude are commonly inferred to represent local rotations of the stress axes. This is most commonly attributed to mechanical layering and the presence of pre-existing structures (e.g. Rubin, 1995; Gudmundsson, 2002; 2011a; Magee et al., 2016). This model implies that intrusions can locally propagate out of the regional $\sigma_{1}-\sigma_{2}$ plane, via Mode I failure of intact rock, or through Mode I dilation of pre-existing structures, producing intrusions that display variable dilation vectors along a single intrusion. Notably, many field examples of sills and dikes exhibit near-parallel dilation vectors, regardless of the intrusion attitude (e.g. Hoek, 1991; Walker, 1993; Airoldi et al., 2011; Martinez-Poza et al., 2014; Muirhead et al., 2014; Eide et al., 2016; Walker et al., 2017). Intrusions that demonstrate shear offset of markers across their margins indicate that during emplacement the dilation vector was inclined from plane normal (Muirhead et al., 2014; Stephens et al., 2017; Walker et al., 2017); this obliquity of opening can be characterised by the opening angle (Fig. 1).

Dilated structures have been studied in detail by Delaney et al. (1986), Baer et al. (1994), and Jolly and Sanderson (1997), who applied mechanical methods to estimate paleostress states using sheet intrusion attitudes. These mechanical models have been adopted for statistical constraints on paleostress axes, and the paleostress state, from vein or dike data (e.g. Sato et al., 2013; Yamaji, 2016). Although several methods exist to determine paleostress axes and a state of paleostress via fault, fracture, or dike data, subhorizontal sheet intrusions (sills) are typically omitted from such 

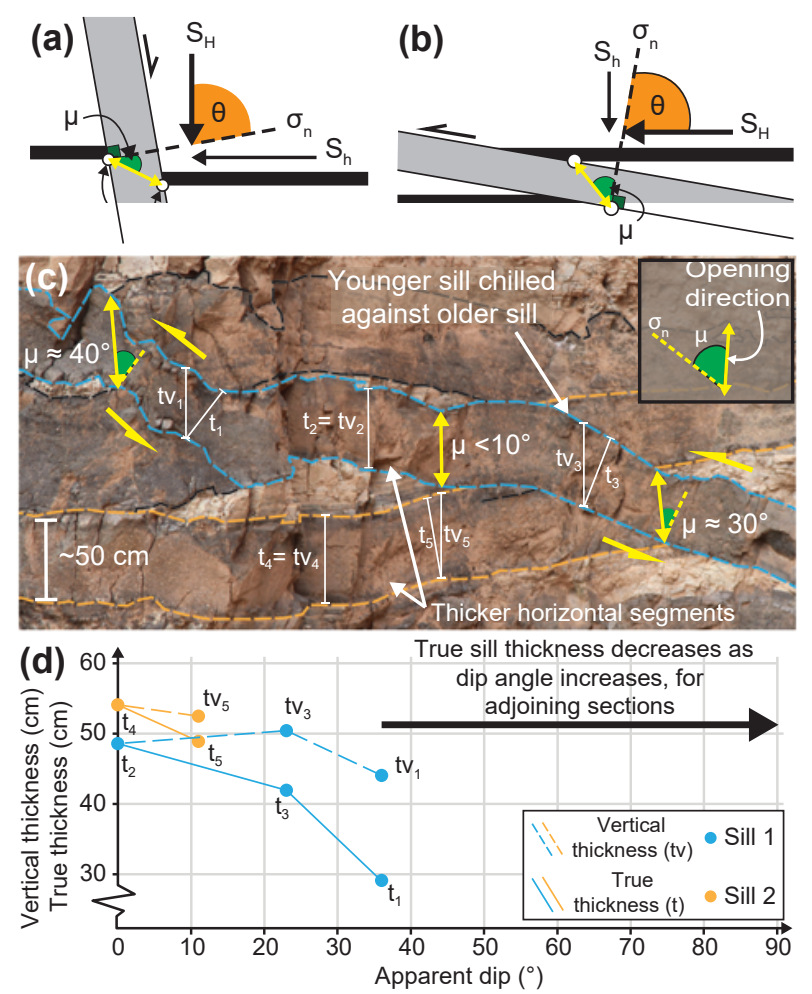

Figure 1. Schematic diagrams to show the dilation direction (yellow arrow) and opening angle $(\mu)$ of fractures in different stress regimes: (a) normal-fault regime (where $S_{\mathrm{H}}=\sigma_{\mathrm{v}}$ ); (b) thrust-fault regime (where $S_{\mathrm{h}}=\sigma_{\mathrm{v}}$ ); the plane attitude is described by $\theta$, the angle between the normal stress and the maximum stress. (c) Example of cross-cutting sills; the middle sill (outlined in blue) shows a consistent vertical opening direction: Mode I opening on horizontal planes and extensional-shear opening on inclined planes. (d) Graph showing changes in vertical thickness, tv, and true thickness, $t$, with changes of apparent dip, for the sills shown in panel (c).

analyses. This is because sill emplacement is commonly associated with a local rotation of the principal stress axes, as a result of bedding or other layer heterogeneities, during regional extension or a low-deviatoric stress state (i.e. where $\sigma_{1} \approx \sigma_{2} \approx \sigma_{3}$; e.g. Gudmundsson, 2011a; Magee et al., 2016). Several studies have demonstrated that sills may also form during tectonic horizontal shortening, in which the minimum principal stress is vertical (Walker, 2016; Walker et al., 2017; Stephens et al., 2017); hence sills can be used as paleostress indicators, provided they are accompanied by detailed kinematic characterisation.

Here, we present mechanical models, based on those of Jolly and Sanderson (1997), to determine paleostress state using the attitude of dilated fracture sets; we verify this using the measured opening angle of the intrusions. The method is applicable to any dilated fracture; here we focus on the stress state associated with sill emplacement in the San Rafael subvolcanic field (SRSVF), Utah, and compare these results to fault data in the same area to demonstrate the particular importance of subhorizontal igneous intrusions as records of paleostress.

\section{Dilation of pre-existing fractures}

Dilation of a cohesionless pre-existing planar structure occurs when the fluid pressure $\left(P_{\mathrm{f}}\right)$ exceeds the normal stress on the plane $\left(\sigma_{\mathrm{n}}\right.$; Fig. 1) (Delaney et al., 1986; Jolly and Sanderson, 1997). Normal stress is related to the plane attitude $(\theta)$ and the maximum $\left(S_{\mathrm{H}}\right)$ and minimum $\left(S_{\mathrm{h}}\right)$ principal stresses acting on the plane (Jolly and Sanderson, 1997):

$\sigma_{\mathrm{n}}=\frac{S_{\mathrm{H}}+S_{\mathrm{h}}}{2}+\frac{S_{\mathrm{H}}-S_{\mathrm{h}}}{2} \cos 2 \theta$,

with the range of possible dilatant fracture attitudes controlled by the stress ratio $(\varphi)$,

$\phi=\frac{\sigma_{2}-\sigma_{3}}{\sigma_{1}-\sigma_{3}}$,

and the driving pressure ratio $\left(R^{\prime}\right)$ (Baer et al., 1994):

$R=\frac{P_{\mathrm{f}}-\sigma_{3}}{\sigma_{1}-\sigma_{3}}$.

The stress ratio, $\phi$, is a non-directional value that describes the relative magnitudes of the principal stresses: $\sigma_{3} \leq \sigma_{2} \leq$ $\sigma_{1}$ (here, compressive stresses are positive). The driving pressure ratio $R^{\prime}$ describes the relative magnitudes of the fluid pressure and the remote stress state: when $R^{\prime}<0$ (i.e. $P_{\mathrm{f}} \leq$ $\left.\sigma_{3}\right)$ there is no dilation, and when $R^{\prime} \geq 1$ (i.e. $P_{\mathrm{f}} \geq \sigma_{1}$ ) all fracture attitudes could dilate. This assumes that an intrusion is emplaced during a deviatoric stress state (i.e. where $\left.\sigma_{1} \neq \sigma_{2} \neq \sigma_{3}\right)$; if $P_{\mathrm{f}}>\sigma_{3}$ during a non-deviatoric stress state (i.e. where $\sigma_{1}=\sigma_{2}=\sigma_{3}$ ), all pre-existing fracture attitudes could dilate.

Pre-existing fractures, with poles parallel to the $\sigma_{3}$ axis, will show plane-normal dilation (i.e. dilation parallel to the normal stress vector). Fractures inclined to the plane of $\sigma_{3}$ resolve a shear stress on their surface (Delaney et al., 1986). During dilation, shear stress is reduced to zero through a plane-oblique dilation vector (extensional shear). The angle between the dilation vector and normal stress is defined as the opening angle ( $\mu$; Fig. 1a-c) and represents the ratio of shear to dilation (Delaney et al., 1986). Extensional shear therefore acts to reduce the amount of dilation. For an intrusion comprising inclined and subhorizontal sections, the inclined sections will therefore be thinner than subhorizontal sections oriented perpendicular to $\sigma_{3}$ (e.g. Fig. 1c, d) for a given fluid pressure, providing the stress state is deviatoric and $0<R^{\prime}<1$ (England, 1988). The dilation vector can be measured using traditional compass techniques in the field based on offset piercing points or unique contact geometries, such as recognisable corners in the intrusion walls 


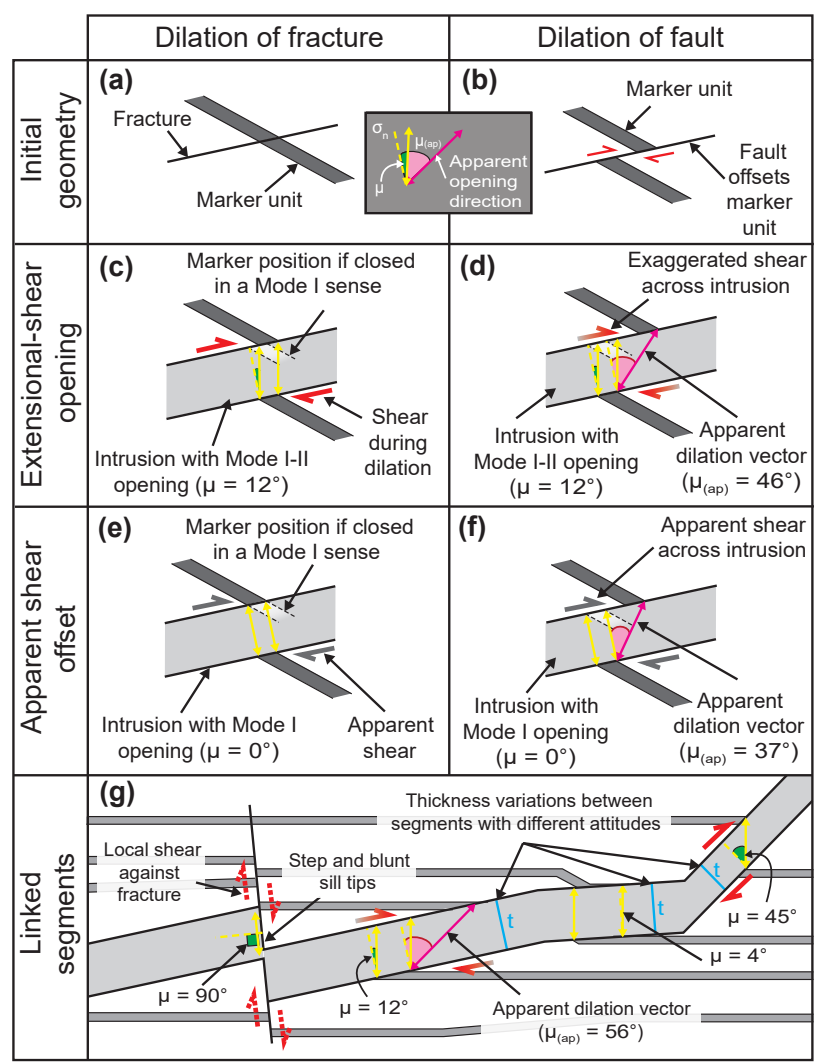

Figure 2. Schematic diagrams to show the relationship between opening mode and apparent shear. (a-b) Initial pre-intrusion geometries with a marker unit oblique to the fracture/fault plane. (cd) Extensional-shear dilation of a pre-existing fracture and fault. (e-f) Mode I dilation of a pre-existing fracture and fault, creating an apparent shear offset. (g) Dilation directions and opening angles along linked segments can be used to infer the true dilation direction and fluid pressure during intrusion. $\mu$ (ap): apparent opening angle.

(e.g. Figs. 1c, 2a, b). True offsets result from extensionalshear opening (Fig. 2c, d); however apparent shear offset can be produced by marker units that are oriented at an oblique angle to the intrusion plane (Fig. 2e) or via dilation of preexisting faults, which produce a larger-than-expected opening angle (Fig. 2f). To determine whether offset and the opening angle are true or apparent, multiple manual measurements of opening angle and intrusion thickness must be made along strike of an intrusion (Figs. 1c, 2g). The opening angle $(\mu)$ of a dilated fracture can be calculated as the inverse cosine of the true thickness ( $t$, normal to the plane) and the vertical thickness (tv, parallel to the dilation vector; Fig. 1c):

$\mu=\cos ^{-1}(t / \mathrm{tv})$.

Alternatively, $\mu$ can be measured as a rake of the obtuse angle between the intrusion contact and the dilation vector, minus $90^{\circ}$. Importantly, this measurement only accounts for the opening angle in two dimensions; movement in or out of the face will not be recorded; therefore dip-parallel sections should ideally be used.

The opening angle is related to the shear stress $(\tau)$, normal stress $\left(\sigma_{\mathrm{n}}\right)$, and fluid pressure $\left(P_{\mathrm{f}}\right)$ acting on that plane at the time of intrusion (Delaney et al., 1986; Jolly and Sanderson, 1997):

$\mu=\tan ^{-1}\left(\frac{\tau}{P_{\mathrm{f}}-\sigma_{\mathrm{n}}}\right)$.

Equation (5) shows that if the fluid overpressure $\left(P_{\mathrm{f}}-\sigma_{\mathrm{n}}\right)$ is equal to the shear stress, the opening angle is $45^{\circ}$, and the shear-to-dilation ratio is unity. If the overpressure is greater than the shear stress, the opening angle is less than $45^{\circ}$, and the fracture will show a greater component of dilation to shear. When $\mu$ is negative, the fracture will remain closed as the fluid pressure did not exceed the normal stress. An intrusive segment, however, may inflate against a closed fracture (where $P_{\mathrm{f}}<\sigma_{\mathrm{n}}$ ), causing a local contractional shear and a blunt intrusion tip (e.g. Fig. 2g).

\section{Mechanical models for fracture dilation and opening angle}

Equation (5) can be represented in three-dimensional (3D) space, for any given stress state, stress ratio, and fluid pressure: Fig. 3 shows the opening angle $(\mu)$ of all possible fracture planes in 3-D space, plotted as colour-contoured pole-to-plane values of $\mu$, on equal-area lower-hemisphere stereographic projections and on 3-D Mohr diagrams. Fluid pressure was calculated at five equal intervals, which are expressed as $R^{\prime}$ values (Fig. 3a), relative to the ambient stress state. Figure 3 shows plots of opening angles for three tectonic regimes in which $\phi$ is 0.5 : (1) a thrust-fault regime $\left(\sigma_{\mathrm{v}}=\sigma_{3}\right)$ (Fig. 3b), (2) a strike-slip regime $\left(\sigma_{\mathrm{v}}=\sigma_{2}\right)$ (Fig. 3c), and (3) a normal-fault regime $\left(\sigma_{\mathrm{v}}=\sigma_{1}\right)$ (Fig. 3d). The principal stress attitudes are constant in all models, with the azimuth for the maximum horizontal stress $\left(\sigma_{\mathrm{H}}\right)$ trending E-W. All planes are modelled as cohesionless surfaces.

The models complement the results of Jolly and Sanderson (1997) and demonstrate that within a given stress state, increasing the fluid pressure increases the range of preexisting fracture attitudes that can dilate, provided the dilated fracture is linked to the magmatic source. The models also show that for any given fracture, increasing $P_{\mathrm{f}}$ decreases $\mu$. Where $\sigma_{3}<P_{\mathrm{f}} \leq \sigma_{2}$ (Fig. 3b-d, i-ii), the dilation zone, delineating the poles to fractures that are predicted to dilate forms an ellipse about the $\sigma_{3}$ axis and is elongate in the direction of the intermediate stress $\left(\sigma_{2}\right)$; only fractures with poles parallel to the $\sigma_{3}$ axis show Mode I opening. If $\sigma_{2}<P_{\mathrm{f}}<\sigma_{1}$ (Fig. $3 b_{\mathrm{iii}}-\mathrm{d}_{\mathrm{iii}}$ ) the dilation zone forms a girdle parallel to the axis of $\sigma_{2}$, with two defined zones of nearMode I opening $\left(0-10^{\circ}\right)$ surrounding the $\sigma_{2}$ and $\sigma_{3}$ poles. Fractures of all attitudes can dilate if $\mathrm{P}_{\mathrm{f}}=\sigma_{1}$ (Fig. $3 b_{\mathrm{iv}}-\mathrm{d}_{\mathrm{iv}}$ ). The models suggest that Mode I opening of pre-existing frac- 
(a) Principal stresses and
relative fluid pressure
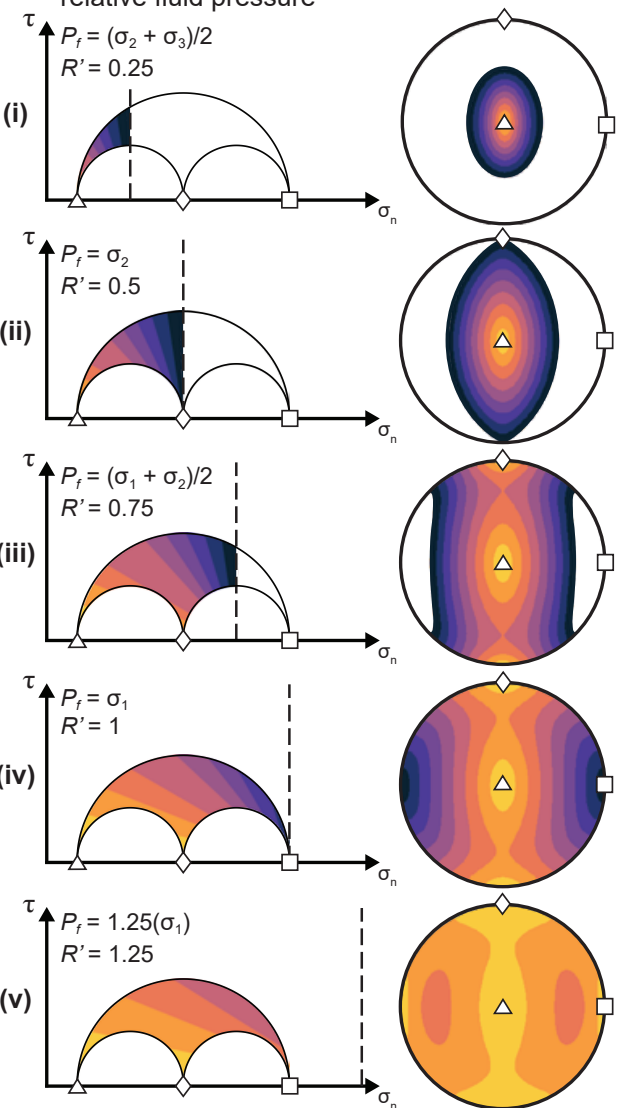

$\square^{\sigma_{1}} \diamond \sigma_{2} \quad \Delta \sigma_{3} \quad$ Opening angle $(\mu)$

(b) Sill: $\sigma_{\mathrm{v}}=\sigma_{3}$
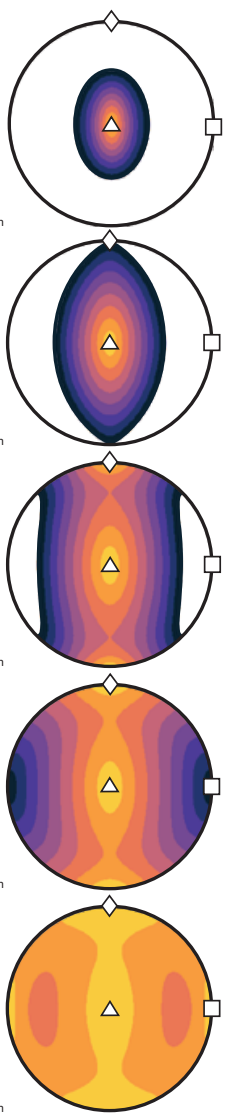

(C) Dike: $\sigma_{\mathrm{v}}=\sigma_{2}$
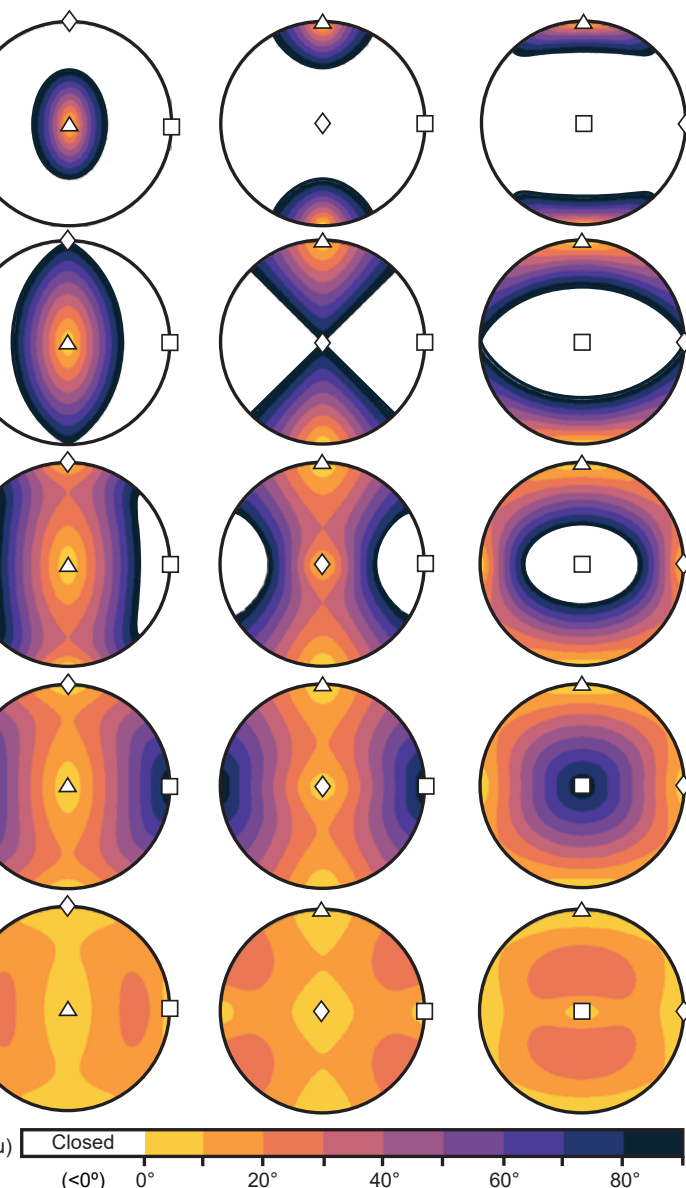

(d) Dike: $\sigma_{v}=\sigma_{1}$
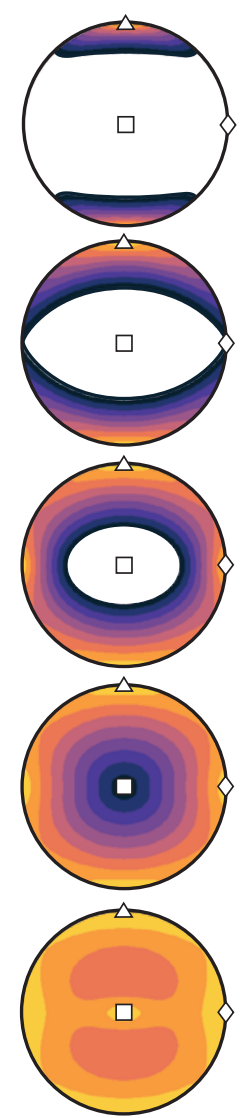

$80^{\circ}$

Figure 3. Mechanical models showing contoured fracture-opening angles for various stress and fluid pressure conditions, using the equation from Delaney et al. (1986), projected onto lower-hemisphere, equal-area stereonets and Mohr circles (colour scheme from Thyng et al., 2016).

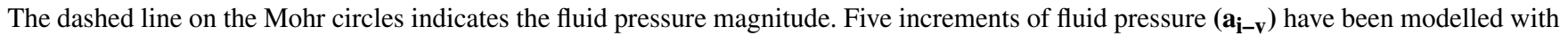
three stress states: (b) thrust-fault regime $\left(\sigma_{\mathrm{v}}=\sigma_{3}\right)$, (c) strike-slip regime $\left(\sigma_{\mathrm{v}}=\sigma_{2}\right)$, and (d) normal-fault regime $\left(\sigma_{\mathrm{v}}=\sigma_{1}\right)$. Colour contours correspond to pole-to-plane values. Poles that plot in the yellow zone (where $\mu=0-10^{\circ}$ ) will display approximately plane-normal opening; poles with larger opening angles will display extensional-shear dilation and have a smaller true thickness than adjoining segments that plot in the yellow zone.

tures should only be common if the fluid pressure exceeds $\sigma_{1}$ (e.g. Fig. $3 b_{v}-d_{v}$ ). For dilation of misoriented cohesionless fractures, with planes oriented at a high angle to $\sigma_{3}$, a higher fluid pressure is required to overcome the normal stress acting on their surface (e.g. Gaffney et al., 2007). Importantly, if misoriented planes do not become linked to the fluid network, high fluid overpressures will be relaxed by dilation of preferentially oriented pre-existing structures, or via failure of intact rock (e.g. Sibson, 2012). Dilational fracture data should therefore plot stereographically with the greatest density of poles to planes about the $\sigma_{3}$ axis (Jolly and Sanderson, 1997; Yamaji et al., 2010). Propagating intrusions may cut across or terminate against misoriented structures, which plot in the zone of no dilation (white areas on the Mohr circles and stereonets; Fig. 3), as the normal stress acting on these planes exceeds the fluid pressure, preventing dilation (e.g. Gaffney et al., 2007; Gudmundsson, 2011a). Terminated intrusions may inflate against closed fractures if magma supply continues; dilation will be accommodated by local shear along the closed fracture, producing a blunt intrusion tip (Baer, 1991; Stephens et al., 2017). Through measurement of the opening angles of veins or intrusions, and determining the distribution of fracture attitudes that are in contact with intrusions, but not dilated, it is therefore possible to constrain the fluid pressure relative to the ambient stress state.

In addition to changes in fluid pressure, fracture dilation is also sensitive to changes in remote stress, particularly at lower $P_{\mathrm{f}}$. For instance, where $\sigma_{3}<P_{\mathrm{f}} \leq \sigma_{2}$ (Fig. 3b$\mathrm{d}$, i-ii) each stress regime is defined by a particular range of fracture attitudes, with a unique opening angle pat- 
tern. Where $\sigma_{2}<P_{\mathrm{f}} \leq \sigma_{1}$ (Fig. 3b-d, iii-iv), the thrust-fault regime (Fig. $3 b_{\text {iii-iv }}$ ) and strike-slip regime (Fig. $3 c_{\text {iii-iv }}$ ) have similar opening angle patterns, whereas the distribution of attitudes and opening angles for the normal-fault regime (Fig. $3 \mathrm{~d}_{\text {iii-iv }}$ ) is unique. Applied carefully, using detailed kinematic field analyses of sills, and their associated deformation, the method has the potential to discriminate among intrusions related to different remote stress states. Here, we have applied this method to igneous sills in the SRSVF in Utah.

Dilated fractures, created during the same dilational event, will produce a unique distribution of opening angles when plotted stereographically as poles to planes (e.g. Jolly and Sanderson, 1997; Yamaji et al., 2010; Sato et al., 2013). Whether this is a tight cluster or a distributed set of poles, the pattern is usually interpreted to represent a single event, governed by one fluid pressure (e.g. Jolly and Sanderson, 1997); however, it is possible that the data represent multiple events caused by fluid pressure pulses of varying magnitude (Yamaji et al., 2010). As the opening angle represents the ratio of shear to dilation (Delaney et al., 1986), magmatic events of varying magnitude within the same governing stress state could produce cross-cutting intrusions with similar geometries but different opening angles (e.g. Fig. 3). The attitude and opening angle of dilated fractures, along with cross-cutting relationships, can therefore be used to identify whether a network of dilated fractures represents one, or multiple, fluid pressure pulses and the stress state during each pulse.

\section{Stress state model for sill emplacement: San Rafael subvolcanic field}

The SRSVF is located in the north-western Colorado Plateau, central Utah (Fig. 4a), and comprises numerous sills, dikes, and volcanic breccia bodies (Fig. 4b, c). The close spatial association of these different intrusive bodies has been suggested to reflect emplacement during a low deviatoric stress state (Delaney and Gartner, 1997; Richardson et al., 2015). No crustal magma chambers have been identified as the source for the intrusive complex (Delaney and Gartner, 1997). The exposed intrusive system was emplaced at $\sim 1 \mathrm{~km}$ depth, within the Middle Jurassic sedimentary rocks of the San Rafael Group, which comprises four formations: the Carmel Formation (siltstone and shale), Entrada Sandstone (interbedded sandstone, siltstone, and claystone), Curtis Formation (interbedded glauconitic sandstone, and siltstone), and the Summerville Formation (siltstone, sandstone, and shale) (Gartner, 1986; Richardson et al., 2015). The sequence represents a paralic environment, with near-shore and shallow marine deposits (Gartner, 1986; Peterson, 1988). The sills are mainly emplaced within the Entrada Sandstone; however they also cut across formation boundaries to intrude the Carmel and Summerville formations (e.g. Fig. 4d; Walker et al., 2017). Richardson et al. (2015) highlighted an example of a dike-to-sill transition for the Cedar Mountain sills (Fig. 4b). Our study focuses on sills in the southern SRSVF (Fig. 4b), and we cannot confirm that relationship here. In our study area, sills and dikes display mutual cross-cutting relationships (e.g. Fig. 4e; Gartner, 1986; Walker et al., 2017), and we have observed no dike-sill transitions for the major sills (e.g. Fig. 4c). Delaney and Gartner (1997) determined ages of dike emplacement between 4.6 and 3.7 Ma; the field relationships therefore constrain sill emplacement to a $\sim 1$ Myr interval.

Walker et al. (2017) interpret the sills in the SRSVF as low-angle conjugate intrusions, and concluded that the sills record a phase of horizontal tectonic shortening, rather than relating to local deflections due to material layering. The sills range from $<10 \mathrm{~cm}$ to $\sim 30 \mathrm{~m}$ thick and are discordant to bedding, with dips of $1-25^{\circ}$ (Fig. $4 d$, f). Based on sill attitude measurements over kilometre-scale outcrops, Walker et al. (2017) showed that sill poles cluster about a near-vertical axis with two defined clusters: a NW- and SE-dipping set in the northern SRSVF and a NE- and SW-dipping set in the southern SRSVF. This study focuses on the NE- and SWdipping sills in the southern SRSVF (Fig. 4b, c).

Across all scales, we find mutual cross-cutting relationships between sills with bimodal dips (e.g. Figs. 1c, 5a-c), and en-echelon sill segments which define low-angle $\left(\sim 20^{\circ}\right.$ dip) conjugate sets (Fig. 5a). Deformation bands and gypsum veins have comparable attitudes to sills and thrust faults in the field area and define low-angle conjugate sets with NE and SW dips (Fig. 5d-i). Sills intruded and have been cut by low-angle fractures, thrust faults, and reverse faults (all referred to as thrust faults henceforth) and either cut or abut against sub-vertical fractures (Figs. 4d, 5f; Walker et al., 2017). A constant near-vertical opening direction is noted across all sill segment attitudes (Figs. 6, 7a). Local sill contact data display a range of dips from 4 to $87^{\circ}$ with horizontal to subhorizontal sill segments $\left(0-20^{\circ}\right.$ dip $)$ showing plane-normal (Mode I) and extensional-shear dilation $\left(\mu=0-20^{\circ}\right)$, respectively (Figs. 6a, 7a). Inclined segments (20-56 dip) are consistently thinner than adjoining horizontal segments and display reverse-sense shear offset of piercing points $\left(20^{\circ}<\mu \leq 75^{\circ}\right.$; Fig. 7a). Subvertical to vertical fractures $\left(<70^{\circ} \mathrm{dip}\right)$ were not intruded (Fig. 7a), suggesting that fluid pressure was less than the normal stress on those planes during intrusion, and the opening angle was $<0^{\circ}$.

Since the range of dilated sill attitudes is known, we can determine the relative stress and fluid pressure using the parameters $\phi$ and $R^{\prime}$. We calculate these parameters stereographically, using an adapted method from Jolly and Sanderson (1997). The local sill contact data are plotted as poles to planes and coloured by their $\mu$ value; the pole cluster showing Mode I opening $\left(\mu=0-10^{\circ}\right)$ is fitted with an ellipse (Fig. 7b). For data with a clustered distribution, this ellipse geometry provides a guide for the total range of dilated fractures, for which blunt tips define the limit of fracture at- 

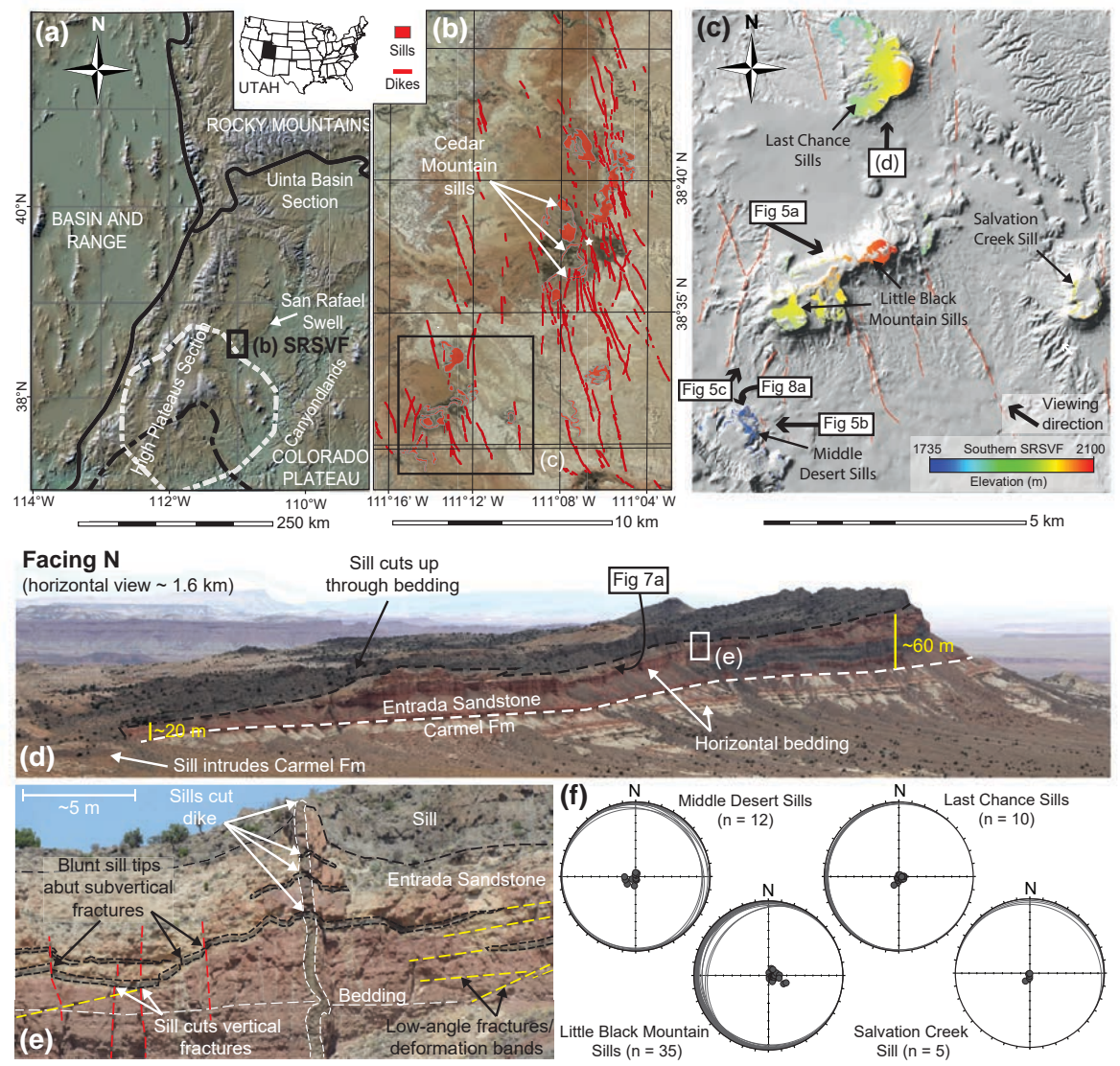

Figure 4. Location maps for the San Rafael subvolcanic field in Utah amended from Walker et al. (2017). (a) Digital elevation model for Utah, showing major structural and depositional areas of the Colorado Plateau. Solid black line shows province boundaries. Dashed black line is a region of lower-crustal delamination and crustal thinning detailed in Levander et al. (2011); dashed white line is their outline of a downwelling body at $200 \mathrm{~km}$ depth, estimated from body wave tomography. (b) Aerial imagery for the San Rafael subvolcanic field (SRSVF) highlighting location and distribution of intrusive bodies; the white star marks the Cedar Mountain sill studied by Richardson et al. (2015). (c) Hillshaded digital elevation models for thick sills in the southern SRSVF, coloured to show extrapolated elevation data for sill top contacts (modified from Walker et al., 2017). (d) Field photograph of the Last Chance sills, which transgress through the stratigraphy; the upper sill cuts across the Carmel-Entrada Formation boundary. (e) Sills cut dike and cut and abut against subvertical fractures (sills outlined in black, dike in white). (f) Lower-hemisphere stereographic projections show sill top contact polygon attitudes (extrapolated from panel c) as great circles, and poles to planes for each sill system (data from Walker et al., 2017).

titudes able to dilate; beyond this is the zone of no opening (where $\mu<0^{\circ}$; Fig. 7b). The minimum compressive stress $\left(\sigma_{3}\right)$ plots in the centre of the Mode I ellipse (which likely coincides with the centre of the data cluster); $\sigma_{1}$ and $\sigma_{2}$ are mutually orthogonal to this (Fig. 7c). If the data have a girdled distribution, the $0-10^{\circ}$ ellipse should be used as an approximation for the geometry of the zone of no opening. In these cases, there will be two clusters of poles where $\mu=0$ $10^{\circ}$ (see Fig. $3 b_{\text {iii }}-\mathrm{d}_{\mathrm{iii}}$ ); the larger ellipse signifies the location of $\sigma_{3}$. A distributed set of dilated fractures may contain several zones of Mode I opening ( $\mu=0-10^{\circ}$; see Fig. 3): $\sigma_{3}$ will plot in the larger of these ellipses and $\sigma_{1}$ in the zone of highest opening angle, or the smallest Mode I ellipse when $P_{\mathrm{f}}$ exceeds $\sigma_{1}$ (see Fig. $3 \mathrm{~b}_{\mathrm{v}}-\mathrm{b}_{\mathrm{v}}$ ).

Field data for sills in the SRSVF can be fitted to an elliptical region on the stereonet with a NW-SE long axis (Fig. 7b), giving horizontal NE-SW maximum compression where $\sigma_{1}$ plunges $3^{\circ}$ towards $068^{\circ} ; \sigma_{3}$ is vertical, plunging $87^{\circ}$ towards $265^{\circ}$; and $\sigma_{2}$ is horizontal, plunging $1^{\circ}$ towards $158^{\circ}$ (Fig. 7c). Using the stereonet data in Fig. 7c, we derive the angles $\theta_{1}$ and $\theta_{2}$, which are used to calculate the stress ratio $(\phi)$ and driving pressure ratio $\left(R^{\prime}\right)$ by Jolly and Sanderson (1997):

$\phi=\frac{1+\cos \left(2 \theta_{2}\right)}{1+\cos \left(2 \theta_{1}\right)}$,

and

$R^{\prime}=\frac{1+\cos \left(2 \theta_{2}\right)}{2}$,

where $\theta_{1}$ is the angle between the $\sigma_{2}$ axis and the perimeter of the dilational ellipse and $\theta_{2}$ is the angle between the $\sigma_{1}$ 

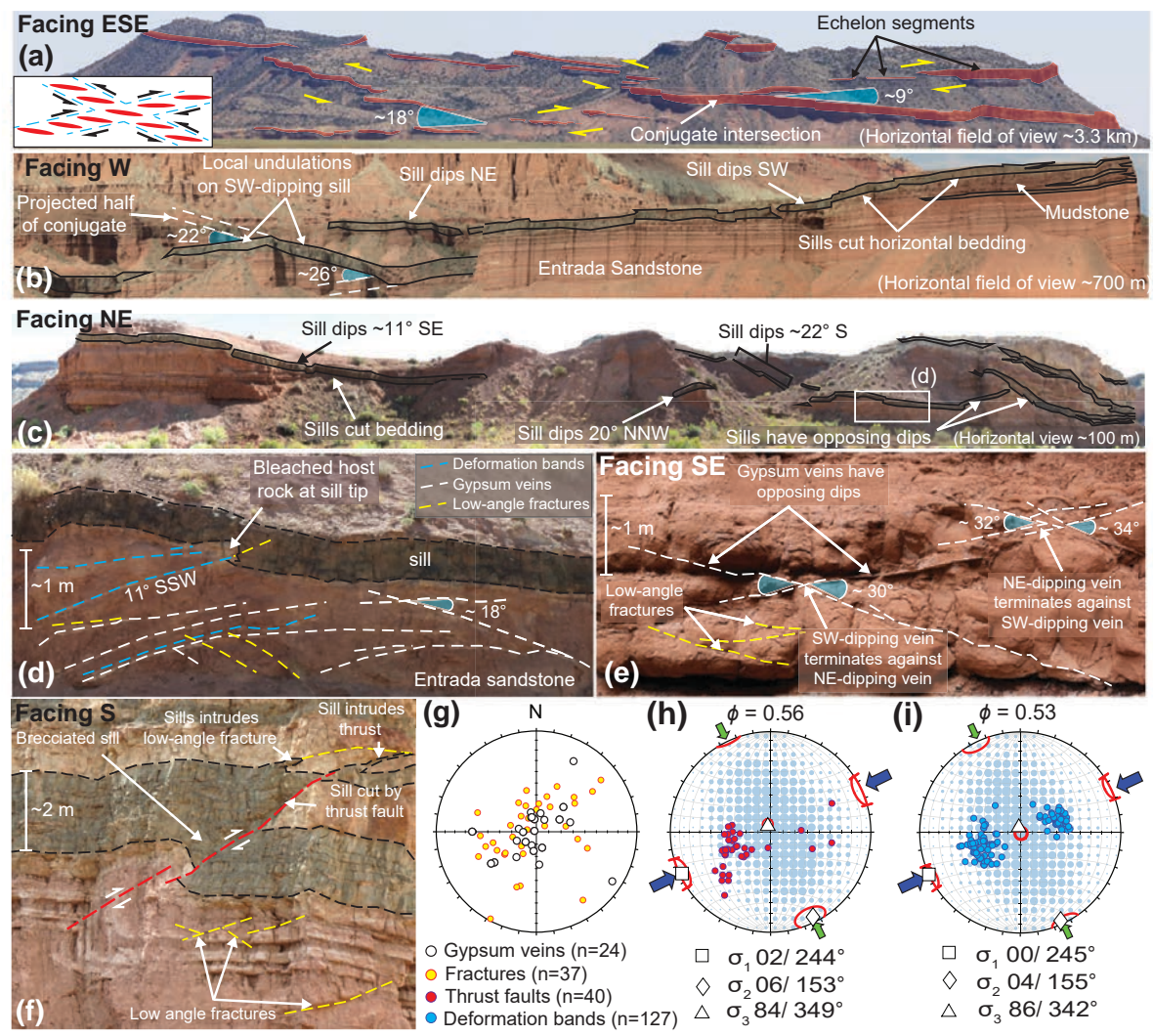

Figure 5. Sill geometry and paleostress analyses of deformation structures in the San Rafael subvolcanic field. (a) Kilometre-scale segmented sills show en-echelon stepping consistent with conjugate faults (sills shaded red). Inset shows schematic interpretation. (b) The $100 \mathrm{~m}$ scale sills showing NE and SW dips (sills outlined in black). (c) The $<100 \mathrm{~m}$ scale sills with bimodal dips (sills outlined in black). (d) Deformation bands and low-angle fractures parallel to gypsum veins. (e) Gypsum veins with conjugate geometries. (f) Sill intruding and cut by a thrust fault and low-angle fractures (sills outlined in black). (g-i) Lower-hemisphere equal-area projections showing (g) gypsum veins and fractures, (h) thrust faults, and (i) deformation band data; principal stress axes calculated for panels (h) and (i) using the right dihedra method (Delvaux and Sperner, 2003). Calculated stress axes given as plunge-trend measurements; $\phi$ value is the stress ratio $\left(\sigma_{2}-\sigma_{3} / \sigma_{1}-\sigma_{3}\right)$.

axis and the dilational ellipse (Jolly and Sanderson, 1997). When an ellipse can only be fitted to the zone of no dilation, Jolly and Sanderson (1997) provide an alternative method for calculating $\phi$. The $R^{\prime}$ value is two-dimensional (2-D); it does not take into account the magnitude of $\sigma_{2}$. The threedimensional relationship between the fluid pressure and all principal stresses is illustrated by the ellipse geometry on the stereonet (Fig. 7c, d), and can also be visualised through construction of a 3-D Mohr circle (Fig. 7e).

The calculated $\phi(0.77)$ and $R^{\prime}(0.68)$ values define the stress ratio and driving stress used to create the opening angle mechanical model (Fig. 7d). For the model, we assigned a minimum vertical stress of $25 \mathrm{MPa}$ to simulate a $\sim 1 \mathrm{~km}$ emplacement depth (Gartner, 1986). Development of extensional-shear fractures requires a low differential stress $\left(\sigma_{\mathrm{D}}: \sigma_{1}-\sigma_{3}\right): 4 T<\sigma_{\mathrm{D}}<5.66 T$; compressional shear faults require that $\sigma_{\mathrm{D}}>5.66 T$ ( $T$ is the host rock tensile strength; Sibson, 2003). Due to the bimodal (conjugate) dip distribution of the sills, their consistent near-vertical opening direction, and the mutual cross-cutting and intrusive relationship between thrust faults and sills, we estimated that $\sigma_{\mathrm{D}}=6 T$. We estimate the tensile strength of the host rock at $1 \mathrm{~km}$ depth to be $3 \mathrm{MPa}$, giving $\sigma_{\mathrm{D}}=18 \mathrm{MPa}$. It should be noted, however, that due to the nature of the model, providing all parameters are scaled relative to $T$, the value of $T$ does not change the resulting opening angle pattern, only the magnitudes of the principal stresses and fluid pressure. $\phi(0.77)$ and $R^{\prime}(0.68)$ derived in the model indicate a mild horizontal radial compression during emplacement, with fluid pressure less than $\sigma_{2}$ (Fig. 7d, e).

The measured opening angles of the studied sills fit with the contouring of a single ellipse (Fig. 7d), suggesting that during the intrusion of sills in the study area, the fluid pressure and stress state remained relatively constant. However, we acknowledge that a broader study across the SRSVF may reveal spatio-temporal fluctuations in either the stress regime or magma pressure. 


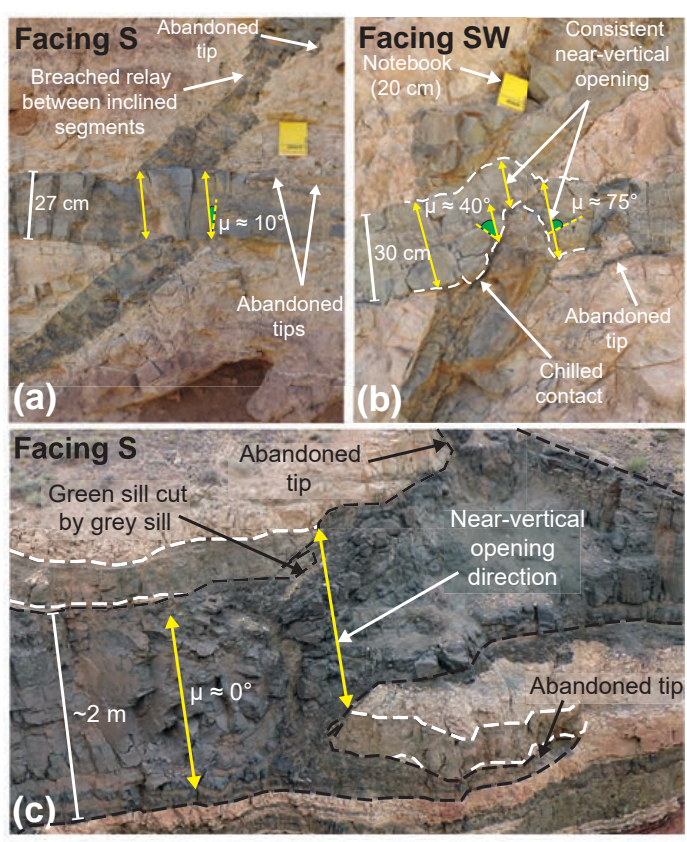

Figure 6. Sill-sill cross-cutting relationships. (a) Younger horizontal sill maintains a constant thickness when cutting older sill. (bc) Inclined sill sections are thinner than horizontal sections. All sills show near-vertical opening directions, regardless of attitude.

\section{Discussion}

\subsection{Sill geometry as a record of far-field stress}

Sills in the SRSVF are mildly transgressive, in that although they have intruded parallel to bedding at a local scale (e.g. Fig. 5b, c, f), at the field-scale they cut across the stratigraphy at a low angle (Figs. 4d and 5a-b; Walker et al., 2017). Transgressive sill geometries are typically inferred to represent either the peripheral section of a saucer-shaped sill (e.g. Malthe-Sørenssen et al., 2004) or a low-angle cone sheet emanating from a magma chamber (e.g. Gudmundsson, 2006; Martí and Geyer, 2009). In either case, the transgressive segments should have an overall centripetal dip distribution. No magma chamber has been identified in the SRSVF, and the sills do not dip towards a central source, nor do they have a saucer-shaped geometry. Sills in the SRSVF show consistent bimodal dip patterns, with mutual cross-cutting relationships, at the outcrop to field scale (i.e. for sills that are centimetres to tens of metres thick). We infer, as noted by Walker et al. (2017), that the bimodal sill geometry is representative of low-angle conjugate faults, which required a deviatoric stress state $\left(\sigma_{\mathrm{D}}>5.66 T\right.$; Sibson, 2003) during emplacement.

At the local (centimetre-metre) scale, the SRSVF sills display a range of attitudes with consistent vertical opening directions and attitude-dependent thickness variations. In a low-deviatoric stress state, local variations in intrusion attitude are traditionally inferred to represent rotations of the principal stress axes, which may be caused by the effects of mechanical layering (e.g. Gudmundsson, 2011a), or preexisting faults and fractures (e.g. Fossen, 2010; Magee et al., 2013). Local stress rotations would therefore cause intrusions of any attitude to dilate in a Mode I sense, producing a polymodal distribution of opening directions across an intrusive suite. In that case, the aperture (true thickness) of the segment would be dominantly controlled by the host rock elastic properties (mainly Young's modulus, E) (e.g. Brenner and Gudmundsson, 2004). Units with low $E$ are less stiff than those with high $E$; i.e. a low $E$ material will accrue more strain for a given stress. Accordingly, when a fluid-filled fracture, with constant fluid pressure, cross-cuts units with varying elastic properties, it will have a larger aperture in units with low $E$ and a smaller aperture in units with higher $E$ (Brenner and Gudmundsson, 2004; Gudmundsson, 2011b). Local attitude variations in the SRSVF sills do not correspond solely to bedding interfaces. Although we infer that the inclined sill sections are dilated pre-existing fractures, the consistent vertical opening directions suggest that inclined fractures were subject to extensional shear rather than Mode I dilation. This is supported by the attitude-dependant (rather than lithology-dependent) thickness variations; horizontal sill segments are consistently thicker than adjoining inclined segments, regardless of the hosting lithology.

Areas that host several intrusion sets, with different attitudes, are commonly interpreted to represent discrete and separate intrusive events (e.g. Delaney and Gartner, 1997; Walker, 1993). Our study, however, suggests that the observed range of sill attitudes is indicative of magmatism during a deviatoric far-field stress state (e.g. Walker, 2016; Walker et al., 2017). The sills may, therefore, be equivalent to reverse faults in the area, accommodating horizontal shortening and vertical thickening.

\subsection{Accommodation of shortening: comparing sills and reverse faults in the San Rafael subvolcanic field}

The SRSVF is host to dikes and sills; the sills cut, and are cut by, thrust (and reverse) faults that dip to the NE and SW (Figs. 5f, 8a; Walker et al., 2017). Thrusts, deformation bands, and gypsum veins in the region form conjugate sets (Fig. 5d-i), which record a coaxial horizontal shortening and vertical thickening (Walker et al., 2017). Right dihedra paleostress analysis (using the method of Delvaux and Sperner, 2003) of the thrust faults and deformation bands in the San Rafael show a close correlation with the calculated stress state results for sills, with an angular mismatch among the maximum principal stress axes of $\sim 4^{\circ} ; \phi$ values calculated for the faults are lower than for the sills, at 0.53-0.56 (Fig. 5h, i). For comparison, Bingham analyses (Yamaji, 2016) of the local sill contact data derive an average $\phi$ value of 0.63 and principal stress axes creating a $6^{\circ}$ angular mismatch with the opening angle and right dihedra models (Fig. 8b). To further constrain the stress ra- 


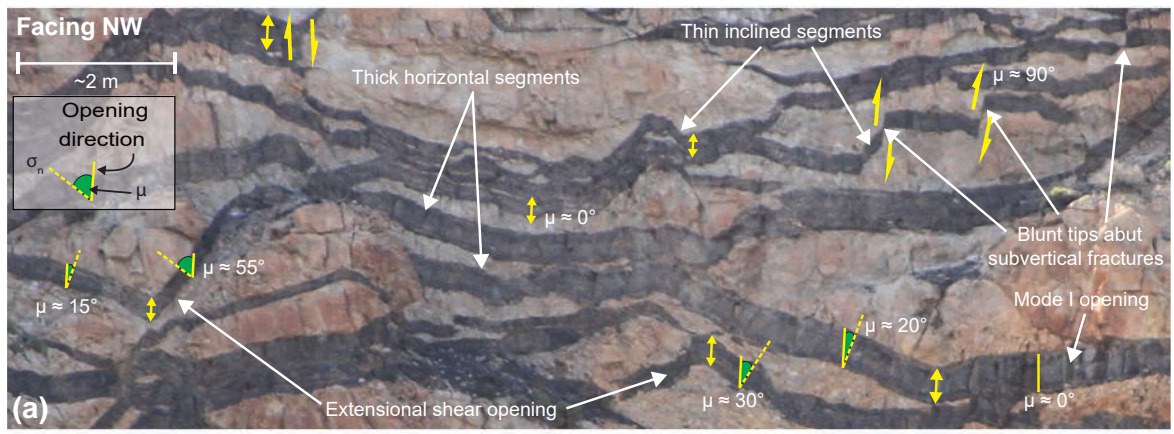

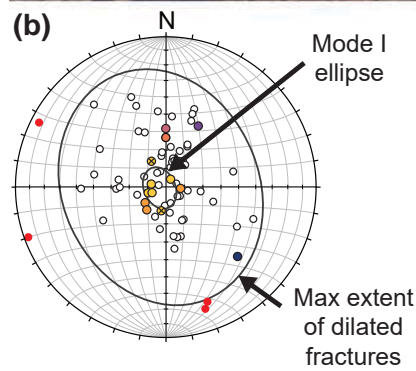

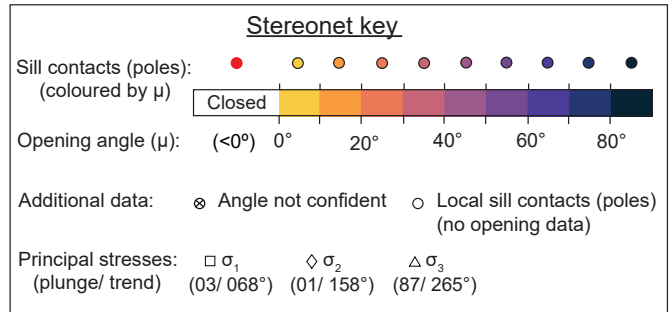

(c)

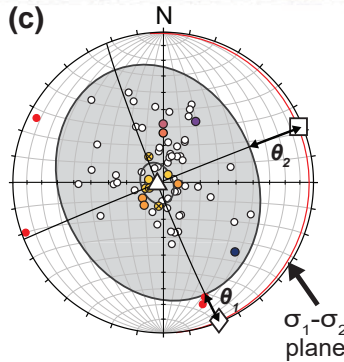

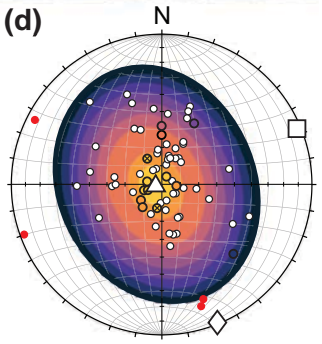

(e)

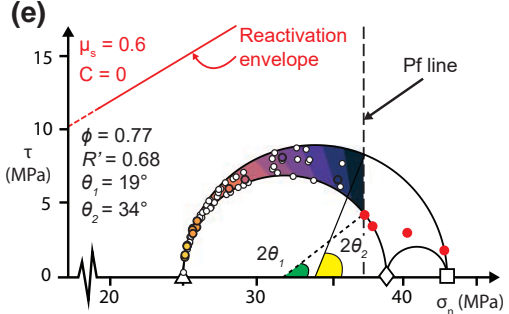

Figure 7. The opening-angle mechanical model. (a) Field example of thin sills $(<1 \mathrm{~m}$ thick) displaying a range of local contact dips and a consistent vertical opening. (b) Lower-hemisphere, equal-area stereonet with local sill contacts plotted as poles to planes, coloured relative to their opening angle, with Mode I and total dilational ellipses constructed. (c) Determination of principal stress axes and $\theta$ angles. (d) Mechanical model results using the stress ratio and driving pressure $\left(\phi=0.77, R^{\prime}=0.68\right.$; see text for details) derived from panel (c). (e) 3-D Mohr circle showing how $\theta_{1}$ and $\theta_{2}$ can be used to calculate relative fluid pressure; the Mohr circle is colour contoured for values of $\mu$; local sill contacts are plotted as poles and coloured by their opening angle.

tio, and the relationship between intrusions and contractional shear structures, we input the thrust fault, deformation band, gypsum vein, and overall sill geometry pole data into mechanical models of normalised slip tendency $\left(T_{\mathrm{s}}\right.$; Fig. 8c) and dilation tendency $\left(T_{\mathrm{d}}\right.$; Fig. $\left.8 \mathrm{~d}\right)$. Although typically used to assess the reactivation potential of pre-existing structures in a present-day stress state (e.g. Ferrill et al., 1999), the models can also be used to fit a paleostress state to field data (e.g. Stephens et al., 2017). Normalised slip tendency $\left(T_{\mathrm{s}}=\left(\tau / \sigma_{\mathrm{n}}\right) / T_{\mathrm{s}} \max\right.$; Morris et al., 1996) and dilation tendency $\left(T_{\mathrm{d}}=\left(\sigma_{1}-\sigma_{\mathrm{n}}\right) /\left(\sigma_{1}-\sigma_{3}\right)\right.$; Ferrill et al., 1999$)$ are calculated from the stresses acting on a plane, or potential plane. This can be used to predict the attitude of both potential failure planes and pre-existing fractures that are susceptible to reactivation in a given stress state. Notably, the zone of high $T_{\mathrm{S}}(0.8-1.0)$ overlaps with the zone of high $T_{\mathrm{d}}(0.8-1.0)$, suggesting a zone of potential extensional shear. To enable conjugate shear failure, we used the same differential stress of $6 T$, where $T=3 \mathrm{MPa}$, as used previously. By fitting the zones of high slip tendency to the combined thrust-fault and deformation band data, and zones of high dilation tendency to the overall sill geometry and gypsum vein data, we were able to derive a best-fit $\phi$ value of 0.65 , with a horizontal NE$\mathrm{SW} \sigma_{1}$ that plots within the $6^{\circ}$ angular mismatch. The $\phi$ value is consistent with the right dihedra ( $\phi=0.53$; Fig. 5h, i), Bingham analysis $(\phi=0.63$; Fig. $8 \mathrm{a})$, and our opening angle models $(\phi=0.77$; Fig. 7). The field observations combined with the paleostress analyses suggest that sill emplacement took place during a state of mild horizontal radial compression.

A key difference between the strains recorded by sills and thrusts is the dominance of dilation during sill emplacement and compressional shear during thrusting. The range of local dips, and consistent vertical opening, suggests that the sills were emplaced by a combination of brittle failure and dilation of pre-existing structures (including thrust faults), in which the fluid overpressure accommodates both shear and dilation. Consistent with the interpretation of Walker 


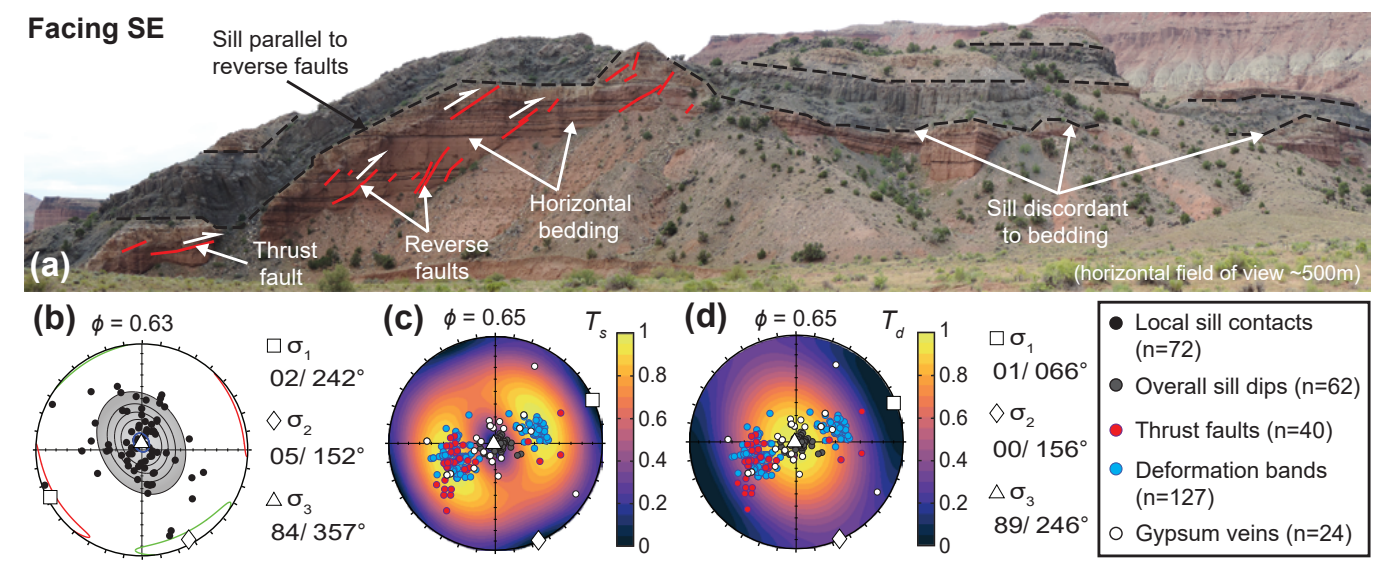

Figure 8. Sill geometry and paleostress analyses of deformation structures in the San Rafael subvolcanic field. (a) Field example for comparison between sill and thrust-fault geometry. (b-d) Lower-hemisphere equal-area projections with calculated stress axes given as plunge-trend measurements. (b) Local sill-host rock contact data; Bingham analysis (Yamaji, 2016) used to calculate principal stress axes, shown with $95 \%$ confidence regions and density contours (shaded region). Panels (c) and (d) are mechanical models contoured for slip tendency $\left(T_{\mathrm{S}}\right.$ ) and dilation tendency $\left(T_{\mathrm{d}}\right)$, respectively.

et al. (2017), our field observations and mechanical model results suggest that the sills represent conjugate intrusions, which record the continuity of horizontal shortening during periods of elevated magmatic pressure.

While the opening angle of dilated fractures has been used here to characterise the paleostress state during dilation of pre-existing cohesionless fractures, we envisage that it could also be applied to extension or extensional-shear fractures, formed via failure of intact rock. In these cases, we would expect the fracture network to resemble a mesh structure (e.g. Sibson, 1996), which comprises predominantly parallel (Mode I) and bimodal (conjugate extensional-shear) fractures, which dip at a low angle to $\sigma_{1}$, with opening angles of $<20^{\circ}$ (e.g. Hancock, 1985; Ramsey and Chester, 2004). Importantly, the models presented in this study can be used to determine whether intrusive suites record changes in the tectonic stress state, or to identify fluid pressure pulses of varying magnitude in a single governing far-field stress state. These attributes have significant implications for improving our understanding of the development of past and presentday magmatic systems.

\section{Conclusions}

Our mechanical models build upon the work of Delaney et al. (1986) and Jolly and Sanderson (1997) to use fracture geometry and opening angles to derive the principal stress axes during sill emplacement and provide crucial new constraints on the stress state and fluid pressure, applicable to dikes, sills, and veins. The geometry of sills in the SRSVF records a continuous horizontal shortening that is otherwise accommodated by contractional faults in the area. Contoured regions on stereonets for opening angles suggest that in a high deviatoric stress state, it should be relatively rare for intrusions to be purely Mode I structures. In such settings, it should be commonplace for intrusions to accommodate a component of shear during their emplacement. Our opening angle model is particularly useful in determining paleostress states for regions where there is little brittle deformation (i.e. faulting), other than intrusions, and it may therefore present a useful and important tool in tectonic and magmatic studies.

Code availability. The FracTend MATLAB code will be made publically available via GitHub in due course. The code is currently being prepared for upload; in the meantime, the code is available upon request from David Healy (d.healy@abdn.ac.uk).

Data availability. Field locations can be found in Fig. 4. The overall sill geometry data used in Fig. 4 are from Walker et al. (2017). The structural field data are available in the Supplement of this work.

\section{The Supplement related to this article is available online at https://doi.org/10.5194/se-9-847-2018-supplement.}

Author contributions. Field data were collected by TLS, AB, and RJW. RJW and $A B$ provided valuable discussions in the field, as well as during paper preparation, along with RWE and DH. DH developed the FracTend MATLAB code. TLS prepared the paper with contributions from all co-authors. 
Competing interests. The authors declare that they have no conflict of interest.

Acknowledgements. This work was undertaken during Tara L. Stephens's PhD studentship, supported by the Central England Natural Environmental Research Council (NERC) Training Alliance (CENTA) (award reference: 1503848). The authors would like to thank Nicolas Le Corvec and the anonymous reviewer for their helpful comments during the reviewing process. Additionally we would like to thank Craig Magee, Atsushi Yamaji, and an anonymous reviewer for their constructive reviews on an earlier version of the paper.

Edited by: Gwenn Peron-Pinvidic

Reviewed by: Nicolas Le Corvec and one anonymous referee

\section{References}

Airoldi, G., Muirhead, J. D., White, J. D. L., and Rowland, J.: Emplacement of magma at shallow depth: insights from field relationships at Allan Hills, south Victoria Land, East Antarctica, Antarct. Sci., 23, 281-296, https://doi.org/10.1017/s0954102011000095, 2011.

Anderson, E. M.: The dynamics of faulting and dike formation with applications to Britain, Oliver and Boyd, Edinburgh, UK, 1951.

Baer, G.: Mechanisms of dike propagation in layered rocks and in massive, porous sedimentary rocks, J. Geophys. Res., 96, 11911, https://doi.org/10.1029/91JB00844, 1991.

Baer, G., Beyth, M., and Reches, Z. E.: Dikes emplaced into fractured basement, Timna Igneous Complex, Israel, J. Geophys. Res.-Sol. Ea., 99, 24039-24050, https://doi.org/10.1029/94JB02161, 1994.

Brenner, S. L. and Gudmundsson, A: Arrest and aperture variation of hydrofractures in layered reservoirs, Geol. Soc. London Spec. Publ., 231, 117-128, 2004.

Delaney, P. T. and Gartner, A. E.: Physical processes of shallow mafic dike emplacement near the San Rafael Swell, Utah, Geol. Soc. Am. Bull., 109, 1177-1192, https://doi.org/10.1130/00167606(1997)109<1177:pposmd>2.3.co;2, 1997.

Delaney, P. T., Pollard, D. D., Ziony, J. I., and McKee, E. H.: Field relations between dikes and joints: Emplacement processes and paleostress analysis, J. Geophys. Res., 91, 4920, https://doi.org/10.1029/JB091iB05p04920, 1986.

Delvaux, D. and Sperner, B.: New aspects of tectonic stress inversion with reference to the TENSOR program, Geol. Soc. London Spec. Publ., 212, 75-100, https://doi.org/10.1144/gsl.sp.2003.212.01.06, 2003.

Eide, C. H., Schofield, N., Jerram, D. A., and Howell, J. A.: Basin-scale architecture of deeply emplaced sill complexes: Jameson Land, East Greenland, J. Geol. Soc., 174, 23-40, https://doi.org/10.1144/jgs2016-018, 2016.

England, R. W.: The early Tertiary stress regime in NW Britain: evidence from the patterns of volcanic activity, Geol. Soc. London Spec. Publ., 39, 381-389, https://doi.org/10.1144/gsl.sp.1988.039.01.33, 1988.
Ferrill, D. A., Winterle, J., Wittmeyer, G., Sims, D., Colton, S., Armstrong, A., and Morris, A. P.: Stressed Rock Strains Groundwater at Yucca Mountain, Nevada, GSA Today, 9, 1-8, 1999.

Fossen, H.: Structural Geology, Cambridge University Press, New York, USA, 2010.

Gaffney, E. S., Damjanac, B., and Valentine, G. A.: Localization of volcanic activity: 2. Effects of preexisting structure, Earth Planet. Sc. Lett., 263, 323-338, https://doi.org/10.1016/j.epsl.2007.09.002, 2007.

Gartner, A. E.: Geometry, emplacement history, petrography, and chemistry of a basaltic intrusive complex, San Rafael and Capitol Reef Areas, Utah, US Geological Survey Open-File Report, 86$81,1986$.

Gudmundsson, A.: Emplacement and arrest of sheets and dikes in central volcanoes, J. Volcanol. Geoth. Res., 116, 279-298, https://doi.org/10.1016/S0377-0273(02)00226-3, 2002.

Gudmundsson, A.: How local stresses control magmachamber ruptures, dike injections, and eruptions in composite volcanoes, Earth-Sci. Rev., 79, 1-31, https://doi.org/10.1016/j.earscirev.2006.06.006, 2006.

Gudmundsson, A.: Deflection of dikes into sills at discontinuities and magma-chamber formation, Tectonophysics, 500, 50-64, https://doi.org/10.1016/j.tecto.2009.10.015, 2011 a.

Gudmundsson, A.: Rock Fractures in Geological Processes, Cambridge University Press, New York, USA, 2011 b.

Hancock, P. L.: Brittle microtectonics: principles and practice, J. Struct. Geol., 7, 437-457, 1985.

Hoek, J. D.: A classification of dike-fracture geometry with examples from Precambrian dike swarms in the Vestfold Hills, Antarctica, Geol. Rundschau, 80, 233-248, https://doi.org/10.1007/BF01829363, 1991.

Jolly, R. J. H. and Sanderson, D. J.: A Mohr circle construction for the opening of a pre-existing fracture, J. Struct. Geol., 19, 887892, https://doi.org/10.1016/S0191-8141(97)00014-X, 1997.

Levander, A., Schmandt, B., Miller, M. S., Liu, K., Karlstrom, K. E., Crow, R. S., Lee, C. T., and Humphreys, E. D.: Continuing Colorado Plateau uplift by delamination-style convective lithospheric downwelling, Nature, 472, 7344, 461-465, https://doi.org/10.1038/nature10001, 2011.

Magee, C., Jackson, C. A. L., and Schofield, N.: The influence of normal fault geometry on igneous sill emplacement and morphology, Geology, 41, 407-410, 2013.

Magee, C., Muirhead, J. D., Karvelas, A., Holford, S. P., Jackson, C. A. L., Bastow, I. D., Schofield, N., Stevenson, C. T. E., McLean, C., McCarthy, W., and Shtukert, O.: Lateral magma flow in mafic sill complexes, Geosphere, 12, 809-841, https://doi.org/10.1130/ges01256.1, 2016.

Malthe-Sørenssen, A., Planke, S., Svensen, H., and Jamtveit, B.: Formation of saucer-shaped sills, Geological Society, London, Special Publications, 234, 215-227, 2004.

Martí, J. and Geyer, A.: Central vs flank eruptions at Teide-Pico Viejo twin stratovolcanoes (Tenerife, Canary Islands), J. Volcanol. Geoth. Res., 181, 47-60, https://doi.org/10.1016/j.jvolgeores.2008.12.010, 2009.

Martínez-Poza, A. I., Druguet, E., Castaño, L. M., and Carreras, J.: Dike intrusion into a pre-existing joint network: The Aiguablava lamprophyre dike swarm (Catalan Coastal Ranges), Tectonophysics, 630, 75-90, https://doi.org/10.1016/j.tecto.2014.05.015, 2014. 
Morris, A., Ferrill, D. A., and Henderson, D. B.: Slip-tendency analysis and fault reactivation, Geology, 24, 275-278, https://doi.org/10.1130/00917613(1996)024<0275:STAAFR>2.3.CO;2, 1996.

Muirhead, J. D., Airoldi, G., White, J. D. L., and Rowland, J. V.: Cracking the lid: Sill-fed dikes are the likely feeders of flood basalt eruptions, Earth Planet. Sc. Lett., 406, 187-197, https://doi.org/10.1016/j.epsl.2014.08.036, 2014.

Peterson, F.: A revision of units in the San Rafael Group and the Morrison Formation, US Geological Survey, Washington, D.C., USA, 1988.

Ramsey, J. M. and Chester, F. M.: Hybrid fracture and the transition from extension fracture to shear fracture, Nature, 428, 63-66, 2004.

Richardson, J. A., Connor, C. B., Wetmore, P. H., Connor, L. J., and Gallant, E. A.: Role of sills in the development of volcanic fields: Insights from lidar mapping surveys of the San Rafael Swell, Utah, Geology, 43, 1023-1026, https://doi.org/10.1130/G37094.1, 2015.

Rubin, A. M.: Propagation of magma filled cracks, Annu. Rev. Earth Pl. Sc., 23, 287-336, 1995.

Sato, K., Yamaji, A., and Tonai, S.: Parametric and nonparametric statistical approaches to the determination of paleostress from dilatant fractures: Application to an Early Miocene dike swarm in central Japan, Tectonophysics, 588, 69-81, https://doi.org/10.1016/j.tecto.2012.12.008, 2013.

Sibson, R. H.: Structural permeability of fluid-driven fault-fracture meshes, J. Struct. Geol., 18, 1031-1042, 1996.

Sibson, R. H.: Brittle-failure controls on maximum sustainable overpressure in different tectonic regimes, AAPG Bulletin, 87, 901-908, https://doi.org/10.1306/01290300181, 2003.

Sibson, R. H.: Reverse fault rupturing: competition between nonoptimal and optimal fault orientations, Geol. Soc. London Spec. Publ., 367, 1, 39-50, https://doi.org/10.1144/SP367.4, 2012.
Stephens, T. L., Walker, R. J., Healy, D., Bubeck, A., England, R. W., McCaffrey, K. J. W.: Igneous sills record far-field and near-field stress interactions during volcano construction: Isle of Mull, Scotland, Earth Planet. Sc. Lett., 478, 159-174, https://doi.org/10.1016/j.epsl.2017.09.003, 2017.

Thyng, K. M., Greene, C. A., Hetland, R. D., Zimmerle, H. M., and DiMarco, S. F.: True colors of oceanography: Guidelines for effective and accurate colormap selection, Oceanography, 29, 9 13, https://doi.org/10.5670/oceanog.2016.66, 2016.

Walker, G. P. L.: Re-evaluation of inclined intrusive sheets and dikes in the Cullins volcano, Isle of Skye, Geol. Soc. London Spec. Publ., 76, 489-497, 1993.

Walker, R. J.: Controls on transgressive sill growth, Geology, 44, 99-102, https://doi.org/10.1130/g37144.1, 2016.

Walker, R. J., Healy, D., Kawanzaruwa, T. M., Wright, K. A., England, R. W., McCaffrey, K. J. W., Bubeck, A. A., Stephens, T. L., Farrell, N. J. C., and Blenkinsop, T. G.: Igneous sills as a record of horizontal shortening: The San Rafael subvolcanic field, Utah, Geol. Soc. Am. Bull., 129, 1052-1070, https://doi.org/10.1130/b31671.1, 2017.

Yamaji, A.: Genetic algorithm for fitting a mixed Bingham distribution to 3D orientations: a tool for the statistical and paleostress analyses of fracture orientations, Island Arc., 25, 72-83, https://doi.org/10.1111/iar.12135, 2016.

Yamaji, A., Sato, K., and Tonai, S.: Stochastic modeling for the stress inversion of vein orientations: Paleostress analysis of Pliocene epithermal veins in southwestern Kyushu, Japan, J. Struct. Geol., 32, 1137-1146, https://doi.org/10.1016/j.jsg.2010.07.001, 2010. 